\title{
ON ELEMENTS OF CULTURALLY INFLUENCED LANGUAGE USE IN THE ADJ ENOUGH TO $V$ CONSTRUCTION IN BRITISH AND AMERICAN ENGLISH'
}

\begin{abstract}
The paper addresses the English ADJ enough to $V$ construction. It first performs distinctive collexeme analysis of the $A D J-V$ pairs appearing in the given construction in American and British English based on the GloWbE corpus. The obtained results are then discussed in view of a model of cross-cultural communication styles and general culture-related knowledge of the two countries. The paper shows that the combination of reliance on a massive corpus approached by a statistical method, the results of which are interpreted qualitatively, can produce some relevant insights into language-culture interrelation. Generally, the paper presents a contribution to the investigation of the language-culture interrelation and belongs to the areas of corpus-based sociolinguistics, usage-based construction grammar and cultural linguistics.
\end{abstract}

Key words: language-culture interrelation, corpus-based sociolinguistics, usagebased construction grammar, distinctive collexeme analysis, models of cross-cultural communication styles

\section{Introduction}

The ADJ enough to $V$ construction in English can be exemplified by the following sentences (all of them taken form the GloWbE - the Corpus of Global Webbased English):

1) The people crazy enough to think they can change the world are the ones who do,

2) Any time I'm foolish enough to think I know what's going on, reality slaps me in the face and shows me just how wrong I am,

\footnotetext{
* Department of English, Faculty of Philosophy, University of Niš, Ćirila i Metodija 2, 18000 Niš, Serbia; e-mail: vladan.pavlovic@filfak.ni.ac.rs

${ }^{1}$ Prepared as a part of the project entitled Innovations in the Teaching Process and Research in the Domains of English Linguistics and Anglo-American Literature and Culture, conducted at the University of Niš Faculty of Philosophy (No. 360/1-16-1-01).
} 
3) As someone who's old enough to remember Biden's first run for the Presidency, I know the Senator from Delaware is bright, but a bit of a loose cannon,

4) It is not important enough to get wired up over.

It takes the form of an adjective phrase that consists of an adjective head, the quantifier enough and a to-infinitive clause functioning as an adjective complement.

In addition, it is a scalar construction with implied relations of causality and a force-dynamic pragmatic relation based on the image schema of enablement (Johnson 1987) established between the scalar attribute expressed by the ADJ-element (or some other element, such as a noun or an adverb, to be addressed below) and the event expressed by the V-element ( $c f$. Bergen and Binsted 2004, Fortuin 2013, 2014; Jensen 2015), which can graphically be represented as follows:

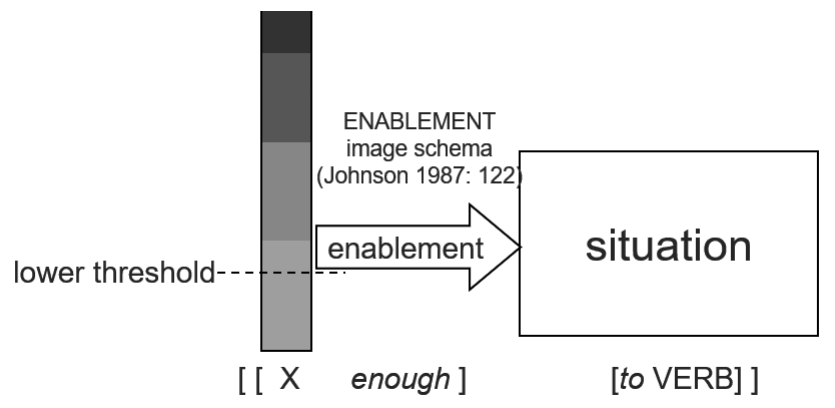

Figure 1. Scale image schema for the Xenough to $V$ construction (taken from Jensen 2015)

An alternative term for the above concept of enablement is sufficiency, according to which "the degree (quantity) of $\mathrm{X}$ is appropriate with respect to a contextually given norm Y (and does not need to be higher)" (Fortuin 2013: 36).

The $A D J$ enough to $V$ construction is usually used predicatively, when it typically functions as a subject complement (She is old enough to be your grandmother) or an object complement (We now consider him experienced enough to entrust him with this task). It can also be used attributively, when it functions as a postnominal modifier ( $\mathrm{He}$ was a person wise enough to know that that couldn't be done that easily).

As indicated above, the first slot in the $X$ enough to $V$ construction need not only be occupied by an adjective, but also by an adverb (I see you read the question carefully enough to notice that the farmer was female!), when the whole construction in question functions as an adverbial. It can also be occupied by a noun, which is then coerced into having scalar-like, ADJ-like features (He waved good-bye to Dominick over his shoulder, relieved that Dom was gentleman enough to let him go without 
further hounding). Jensen (2015) has established that in the COCA (the Corpus of Contemporary American English, available at https://www.english-corpora.org/ coca/), the former case accounts for a total of $21.5 \%$, and the latter for $17.5 \%$ of all the instances of the more abstract $X$ enough to $V$ construction. In other words, the instances of the given construction in which the former element is an ADJ, as the topic of this paper, accounts for the majority (61\%) of the instances of the given more general construction in the COCA.

The given relation of enablement can be: a) "natural", when something may physically be small enough to fit somewhere, light enough to float, or when the weather gets warm enough to move the plants outside, and, more importantly for our purposes in this paper, b) culturally-influenced or culturally-based (man enough to pull the trigger).

With respect to the latter sense of the relation of enablement, Jensen (2017) explored how the $\underline{N}$ enough to $V$ construction (where the $\mathrm{N}$ element are nouns such as man and woman) reflects cultural conceptualisations of gender and behaviour in American English on the basis of the COCA and the collostructional method (to be addressed shortly), and has come to the following conclusions.

The noun man in this construction is co-attracted to verbs that: a) express potentially face-threatening situations, such as accept, admit, ask, own up (Fagin was man enough to admit this professional envy, but only to himself); b) require a certain degree of power (social power, physical power or will power) in the agent, such as fire (an employee), handle, stand up, stick to, protest, wrest (At least he's shown that he's man enough to fire Luzhkov - but he hasn't won yet); c) are related to violence: kill, pull (the trigger), wipe (from the face of the earth) (At least he was man enough to wipe scum like them off the face of the earth). These can be viewed as activities and behaviours that are culturally associated with the given gender category, i.e. that can be thought of as stereotypically male, arguably involving a process of cultural conceptualisation that subsumes cultural metonymy (the social category of "men" is metonymically reduced to stereotypical behavioural features).

The same author has established that the noun woman in the given construction is also co-attracted to verbs that: a) express potentially face-threatening situations: accept, admit, do, stay, take (Your mama shoulda [sic!] been woman enough to tell you the truth straight from the jump!), and b) that require a certain degree of power (primarily will power) in the agent.

The question that naturally follows from this is whether the given patterns of action and behaviours (related to moral strength and willpower) are equally associated with the male and female social categories such that there are no differences between them. The answer that the given author provides is a negative one as man enough to 
$V$ and woman enough to $V$ have a different status in the language system because of their distributional asymmetry (the given author has proposed that there are $89.2 \%$ instances of the former and $10.8 \%$ instances of the latter in the COCA), which makes the former, at present, more conventionalised than the latter.

The most important conclusion emerging from this in view of the purpose of this paper is that it can be claimed that the given construction, and especially the patterns of co-variation (established, as we will see, through rigorous empirical statistical methods) of the collexemes in the N slot, on the one hand, and the V slot, on the other hand, can, at least in some instances, be reflective of the underlying force-dynamic cultural models, and that verbal behaviour can be reflective of underlying cultural conceptualizations.

The aims of this paper are as follows: a) to explore instances of what may be considered culturally-influenced co-attracted collexemes in the ADJ (rather than $\mathrm{N}$, as in the just outlined cases) and $\mathrm{V}$ slots in the given construction; b) to do so not only for American English, but also for British English (henceforward AE and BE), c) to rely thereby on the distinctive collexeme analysis as a type of collostructional analysis applied on the data from a massive e-corpus, and d) to examine thus obtained results in view of (Lewis's) model of cross-cultural communication styles.

The reasons for choosing the given type of collostructional analysis, the two given regional varieties of English and the given model of cross-cultural communication styles will be presented later.

Generally, the paper presents a contribution to the investigation of the languageculture interrelation and belongs to the areas of corpus-based sociolinguistics, usagebased construction grammar and cultural linguistics.

\section{Theoretical background}

This section of the paper will outline some of the studies in culturally influenced language use as well as Lewis's model of cross-cultural communication styles.

\subsection{Studies in culturally influenced language use}

Some of the corpus-linguistic studies addressing culturally-influenced language use (carried out primarily in the areas of sociolinguistics, usage-based construction grammar and cultural linguistics) include Leech and Fallon 1992, Elsness (2013), Ooi (2000), Gries and Stefanowitsch (2004a), Wulff, Stefanowitsch and Gries 2007, Fina 2011, Friginal, 2018, Davies 2018, Sharifian 2017a and 2017b. The above-mentioned Jensen's article from 2017 is an integral part of Sharifian 2017a. 
Here we will focus on only two of the given sources, namely Gries and Stefanowitsch 2004a, and Wulff, Stefanowitsch and Gries 2007, as they also rely on the collostructional method used in this paper.

Gries and Stefanowitsch (2004) investigate the potential dependencies between the two predicate slots in the so-called into-causative ( $V N 2$ into $V$-ing) construction (He tricked me into buying it). They show that such interactions exist, i.e. that cause and result predicates (the V and the V-ing elements) "co-vary" systematically, i.e. that the choices speakers make when filling slots in the construction are influenced by statistically significant interdependencies between these slots (force typically cooccurs with make, bully, push with accept, with some other such pairs being: coerce - do, fool-see, lure-vote).

They then consider two factors influencing this covariation: a cognitive one, based in causative event types (the manipulate, the trigger, the prompt type), and a cultural one, based in knowledge about frames and possible cause-effect relations between them. In other words, these authors claim that most pairs seem to be based in frame-semantic knowledge of varying degrees of culture-specificity about what is likely to cause what, i.e. what frames are cognitively relied on in an entrenched cause-effect relationship in a culture (torture - confess, terrorise - flee, con - pay, mislead - buy). Along the same lines, trickery verbs (mislead, lure, entice, pressure, tempt, fool) constitute the largest single group of cause predicates for the verb buy. Thus, a cultural model emerges of the buyer as a passive participant in the commercial interaction, exploited (and relatively easily so) by others for their own gain. In contrast, the prevalence of verbs of strong coercion and strong negative emotion (panic, force, entrap, terrify) for sell could be evidence that the seller is seen as a more selfdetermined agent, who is less easily coerced than the buyer. The authors conclude that, since the into-causative overwhelmingly encodes a certain type of social interaction, it comes as no surprise that the cultural factor seems to be dominant for this construction.

Wulff, Stefanowitsch and Gries (2007) focus especially on the extent to which the meaning potential of the same construction as above is variety-specific, which is obviously quite important for our purposes in this paper.

Adopting a construction-based view of language (to be briefly outlined later), the given authors demonstrate that it is possible to uncover differences between BE and $\mathrm{AE}$ at the lexico-syntactic level, showing that the collexemes, i.e. the words significantly associated with the construction, are variety-dependent. To this end, they compare more than 5,000 verb pairs as they occur in the two varieties and submit them to distinctive collexeme analysis (also to be addressed in greater detail later), which identifies those verbs that distinguish best between the two varieties. 
Thereby, interesting contrasts emerge, such as the predominance of verbal persuasion verbs in the cause predicate slot of the $\mathrm{AE}$ data as opposed to the predominance of physical force verbs in the cause predicate slot of the BE data. They argue that these and other results create a picture of subtle, yet systematic, differences in meaning construction, which are seen as a reflection of differently entrenched semantic frames.

Talk, they claim, occurs much more frequently than expected in the cause slot of the $\mathrm{AE}$ construction and much less frequently in the cause slot of the BE construction. Thus, the use of this verb in the given construction distinguishes very well between $\mathrm{AE}$ and $\mathrm{BE}$ and hence qualifies as a distinctive collexeme for $\mathrm{AE}$.

British speakers have a much stronger preference to conceptualise causation as physical action in the sense of physical force. American speakers, on the other hand, conceptualise causation via communication / verbal persuasion (hence "brutal Brits and persuasive Americans" from the title of the paper).

In addition, while in $\mathrm{BE}$ the cause predicates typically denote an action by which the causee is set into motion, be it literal or metaphorical motion (sting, provoke, chivvy, stir, stimulate, trigger, etc., as in These stirred us into playing the kit with gusto and enthusiasm), a number of the AE cause predicates denote exactly the opposite concept: verbs such as snooker or rope denote actions by which the causee is not set into motion, but rather fixed to a certain position, restricted in his / her mobility, and thereby forced to undergo some treatment.

Moreover, the given authors claim that the contrast between movementinitializing cause predicates in $\mathrm{BE}$ as opposed to movement-restricting cause predicates in AE may confirm the commonplace perception that British culture lacks the strong and explicit emphasis on mobility as an essential condition for a happy and free life as we find it in American culture. They also claim that the importance of freedom of movement for Americans manifests itself elsewhere in language as well, for instance in the great variety of transportation metaphors in AE as compared to BE.

To conclude, the given paper demonstrates how sophisticated methods such as distinctive collexeme analysis are very useful tools for the investigation of dialectal variation at the lexico-syntactic level. By filtering out those collexemes which are significantly distinctive for either $\mathrm{BE}$ or $\mathrm{AE}$, distinctive collexeme analysis can identify the (mostly subtle) dialectal differences that might otherwise easily escape the naked eye. 


\subsection{Lewis's model of cross-cultural communication}

Lewis's model of cross-cultural communication has been chosen as it is detailed and covers a lot of cultures world-wide, including American and British culture, and addresses how various cultural specificities may get reflected in language, including different (regional) varieties of the same language. As we will see, the communication styles in the USA and Britain are different to varying degrees, so it might be worthwhile to analyse the correlations between the differences in the results obtained for the given varieties, on the one hand, and the corresponding communication styles, on the other hand.

Lewis $(2005,2006)$ has introduced the notion of cultural categories of communication, and classified cultures into linear-active, reactive and multi-active ones (Figure 2).

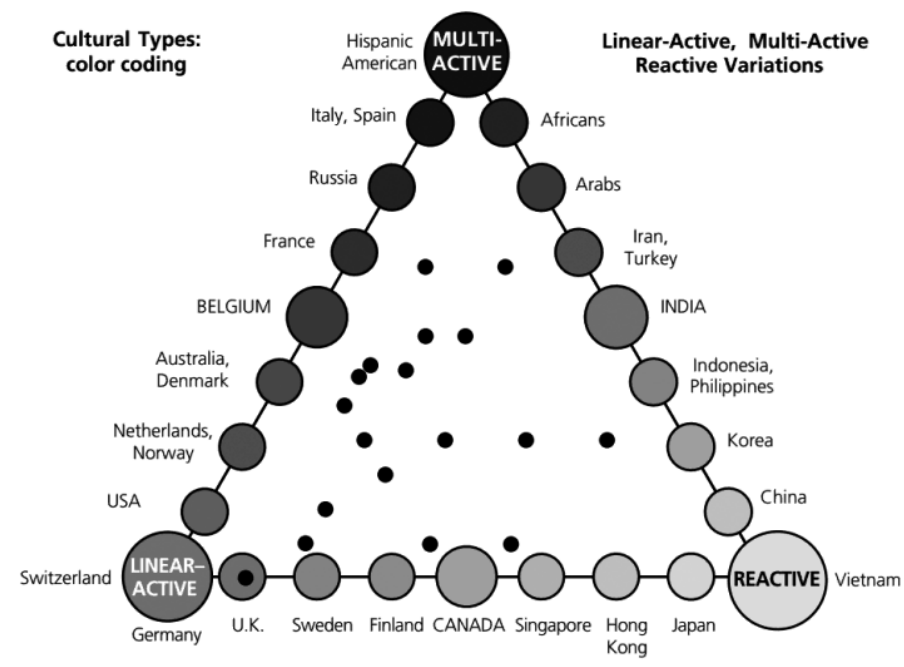

Figure 2. Cultural Types (Lewis 2006: 42)

In this author's view, people belonging to linear-active cultures are generally calm, factual and decisive planners. They prefer straightforward, direct discussion, and they talk and listen in equal proportions. They stick to facts and figures that they have obtained from reliable sources. Multi-actives are warm, emotional, loquacious and impulsive. They often talk in a roundabout, animated way. It is typical of them to speak and listen at the same time, leading to repeated interruptions. They are uncomfortable with silence and seldom experience it among other multi-actives (Lewis 2005: 70, 89). Reactives are courteous, outwardly amiable, accommodating, compromising and good listeners. Their cultures are called "listening cultures". They often seem slow to react 
after a presentation or speech, and when they speak up, it is without clear signs of confrontation (Lewis 2005: 70-71). Before commenting on the relative position of the USA and the UK in view of the given cultural categories of communication, it should be stressed that the given author writes only about broad tendencies and generalizations rather than about any strict divisions between / among various categories he introduces.

The USA can be labelled a linear-active culture with just slight elements of multi-active cultures. In addition, American communication style is typically informal, direct, blunt, tough, pushy, immodest, tending towards the exaggerated and sensational ( $c f$. Lewis 2006). The UK can also be labelled as a linear-active culture, with just slight elements of reactive cultures. British communication style is typically low key, modest, retrained and tenacious. When British people criticise, disagree or even praise, they do it obliquely (using understatement and coded speech). They can accept occasional ambiguities, are prepared to read in-between the lines, like leg-pulling, can show selfdeprecation and tend to use irony ( $c f$. ibid.). Here are some examples of how Americans as opposed to the British may phrase the same propositional content (cf. ibid.): When you scramble, scramble like a son-of-a-bitch vs Speed of action is advisable, We had sticker-shocked the consumers right off their feet vs We had overpriced the product, It's the only game in town vs There is no other choice.

All these differences among the respective communication styles will be relied on in the interpretation of the results obtained.

Other papers in linguistics that are based on at least one of those models include the above-mentioned Fina 2011, as well as Prykarpatska 2008, Ivorra Pérez 2014, and Pavlović 2019. Criticism of the given model (in addition to the criticism of similar models) is available in Piller 2007.

\section{The method and the corpus}

The method used encompasses: a) distinctive collexeme analysis (as a type of collostructional analysis) of the $A D J-V$ pairs appearing in the given construction in the two regional varieties of English; this has helped establish top most strongly attracted and most strongly repelled $A D J-V$ pairs in the given construction in each variety under examination; and b) grouping thus established pairs semantically and approaching them from the perspective of the outlined model of cross-cultural communication. The method used is thus both quantitative and qualitative.

The remainder of this section will briefly present collostructional analysis in general and the steps undertaken to produce the results indicated under b) above. It will also present the corpus used and the general approach (the corpus-based and the corpus-driven ones) to the data obtained. 
Collostructional analysis is a family of quantitative (statistical) corpus-linguistic methods for analysing the relationships between words and the grammatical structures in which they occur, typically used within the theoretical framework of (Goldbergian) Construction Grammar.

It measures the degree of attraction or repulsion that words exhibit to syntactic constructions (hence the term collostruction as a blend of the words collocation and construction). It was developed by Stefan Th. Gries and Anatol Stefanowitsch as an extension of existing collocation-based methods. As opposed to such methods, which focus on purely linear co-occurrence preferences and restrictions pertaining to specific lexical items, collostructional analysis is adapted to the investigation of the lexis-grammar interface and heavily relies on strict quantification and inferential statistics.

The sources involving collostructional analysis include: Gilquin 2006; Gries 2012, 2013, 2014, 2015; Gries and Stefanowitsch 2004a, 2004b; Gries, Hampe and Schönefeld 2005; Hilpert 2014a, 2014b; Stefanowitsch 2005, 2013; Stefanowitsch and Gries 2003, 2005, 2008; and Wulff, Stefanowitsch and Gries 2007, inter alia (some of the given sources were also referred to above). The given sources deal with the collostructional method and its types, with the application of those types to various syntactic constructions (as well as to various types of synchronic and diachronic data regarding syntactic constructions); they also present the software that facilitates the application of the method and discuss the strong and the weaker points of the method, as well as possible misunderstandings of it.

Collostructional analysis is grounded in two frameworks, one theoretical and one methodological. The methodological framework is that of quantitative corpus linguistics. It is characterised by reliance on naturally occurring language data from representative and balanced corpora, which are subjected to strict quantification and statistical evaluation. The theoretical framework consists of grammatical theories that meet the following two criteria. Firstly, they consider grammatical structures at various levels of complexity and schematicity as meaningful in and of themselves, i.e. as signs (form-meaning pairs) and thus not fundamentally different from the lexicon. And secondly, they acknowledge the relevance of frequency distributions of linguistic items. Collostructional analysis is thus applied in the context of various usage-based constructivist approaches to language, including the above-mentioned Goldbergian Construction Grammar ( $c f$. Goldberg 1995, Hoffman and Trousdale 2013).

The basic goal in performing a collostructional analysis is to establish which lexical items are "typical" of a given grammatical construction, i.e. the appearance of which lexical items is statistically significant for the construction in question. 
There are three variants of collostructional analysis, each of them adapted to analysing particular aspects of the relationship between lexical items and grammatical constructions. Those are (simple) collexeme analysis, covarying-collexeme analysis and (multiple) distinctive collexeme analysis. As the former two were not used in this paper, they will not be discussed further.

(Multiple) distinctive collexeme analysis (Gries and Stefanowitsch 2004a, Stefanowitsch 2013) originally aims to establish the differences between two or more alternative constructions (i.e. formally different constructions with a similar meaning) in their respective collocational preferences. More specifically, it establishes which collexemes are over- and underrepresented in each variety at a statistically significant level, i.e. it identifies the lexemes which exhibit a strong preference for one alternative construction type as opposed to the other. It thus makes it possible to identify subtle differences between two apparently synonymous constructions, such as the ditransitive and the prepositional dative construction (He gave Mary the book / He gave the book to Mary). More importantly for the purposes of this paper, it can also be applied in establishing differences in the use of formally one and same construction across various regional varieties (as well as across registers or with respect to any other similar sociolinguistic variable). In this paper, this variant of collostructional analysis is used to establish which $A D J-V$ pairs are over- and underrepresented in the $A D J$ enough to $V$ construction in the two (regional) language varieties at a statistically significant level, i.e. which of them exhibit a strong preference for one variety as opposed to the others.

The corpus used is the GloWbE - the Corpus of Global Web-based English, which is available at https://www.english-corpora.org/glowbe/ for simple searches (for the purposes of this paper, the complete version of the corpus was used which was purchased from professor M. Davies of Brigham Young University, its author). It contains about 1.9 billion words of text from twenty different English-speaking countries published on the Internet in 2012 and 2013 and harvested automatically in a systematic way. For the purposes of this paper, only the AE and BE sections of the given corpus were used.

All the instances of the ADJ enough to $V$ construction were excerpted automatically. It should be noted that it was impossible to precisely identify multiword verbs in the V-slot of the construction (e.g. early enough to let someone else down, ...for not being tough enough to stand up for herself) automatically. This has resulted in the data according to which the $A D J-V$ combination consist of examples such as early - let instead of early - let (somebody) down, or tough - stand, instead of tough - stand up for someone / oneself. Such examples were kept because the full multi-word verb is easily retrievable from the corpus and because they are relatively 
infrequent, so that their inclusion in the (reduced) form cannot possibly jeopardise the integrity of the excerpted material. The same, mutatis mutandis, applies to light verbs - cf. long - make (a decision, as in Obama administration already had over a YEAR and that apparently wasn't long enough to make a decision) and long-decide. The examples in which the infinitive clause contained a simple passive infinitive (not original enough to be protected by copyright), a perfective infinitive (The idea has been successful enough to have caused an upset...), and a perfective passive infinitive (I was privileged enough to have been invited to...), even though they do exemplify the given construction, were removed. This was done because the verbs be and have are auxiliary verbs (rather than main ones) in such clauses, i.e. because their inclusion might have given a wrong impression of which $V$ element it is that the $A D J$ element combines with.

Once databases (available from the author on request) have been established of all the identified $A D J-V$ pairs in the three regional variants, the data outlined in Table 1 below were obtained for performing distinctive collexeme analysis (the $\mathrm{X}$ in the table below stands for either given variety under examination).

\begin{tabular}{|l|c|c|c|}
\hline & $\begin{array}{c}\text { Observed } \\
\text { in variety } \mathbf{X}\end{array}$ & $\begin{array}{c}\text { Observed in } \\
\text { the other variety }\end{array}$ & Total \\
\hline ADJ-V & $\mathrm{A}$ & $\mathrm{b}$ & $\mathrm{a}+\mathrm{b}$ \\
\hline not ADJ-V & $\mathrm{C}$ & $\mathrm{d}$ & $\mathrm{c}+\mathrm{d}$ \\
\hline Total & $\mathrm{a}+\mathrm{c}$ & $\mathrm{b}+\mathrm{d}$ & $\mathrm{a}+\mathrm{b}+\mathrm{c}+\mathrm{d}$ \\
\hline
\end{tabular}

Table 1. Frequency information needed for the multiple distinctive collexeme analysis

These were then entered into spreadsheet files, which were then converted into .txt files and uploaded into $\mathrm{R}$ 3.5.3. The relevant script within the Collostructional Analysis Package prepared by Gries (2014) was used that prompts the user for the relevant quantitative data outlined above.

The results obtained include: 1) the expected frequency of each individual $A D J-V$ pair appearing in the construction in the two regional variants (obtained by means of the chisq.test function), that served as an input for Fisher's exact test used in this kind of analysis; 2 ) the $p$-values produced by Fisher's exact test (as it is well-known, the lower the $p$-value, i.e. the closer it is to zero, the stronger the mutual attraction between the $A D J$ and the $V$ elements, i.e. the less likely it is that the relevant null hypothesis is true); 3 ) the negative base-10 logarithm of the $p$-value as an indicator / index of association strength (cf. Gries, Hampe and Schönefeld 2005; Stefanowitsch and Gries 2005). The 
larger the negative $\log 10$ of the $p$-value, the stronger the mutual attraction. This value is useful because its negative values may indicate which collexemes are repelled (rather than attracted), whereas the $p$-value can only vary from 0 to 1 in the cases of either attraction or repulsion. The $A D J-V$ pairs in each of the varieties were automatically ranked according to the strength of their association to the given construction, starting with those most attracted to it and ending with those most strongly repelled by it (i.e. those that are possible but statistically improbable).

The general approach to thus obtained data was both corpus-based and corpusdriven (cf. Tognini-Bonelli 2001).

The corpus-based approach consists of using the obtained data to test the following hypothesis: the $A D J-V$ pairs in which the $A D J$ element denotes lack of good judgement or intelligence (stupid, dumb, crazy), or presence of good judgement (smart), are statistically more significant in AE rather than in BE. The rationale behind the hypothesis is as follows. Firstly, the inspection of the (simple descriptive) frequency of the given $A D J$ elements in the two varieties in the GloWbE corpus had revealed that it is such adjectives, among others, which occur very frequently. And secondly, it appeared logical that such concrete $A D J$ elements might indeed be more significant for $\mathrm{AE}$ because of the characterization of the dominant communication style in the United States outlined above. In other words, it did not appear logical to expect that such adjectives would be statistically significant for a culture typically characterised by low key, modest and restrained communication, in which, when people criticise, disagree or even praise, they do it obliquely (using understatement and coded speech), such as British culture. On the other hand, the use of the given adjectives to a statistically significant degree was quite expected for the AE data because, as also stated above, American communication style is typically informal, open, direct, blunt, tough, pushy, immodest and tending towards the exaggerated.

The corpus-driven approach is apparent in the fact that the paper also attempts to simply establish what results the given kind of statistical analysis yields and how (if at all) they too might be approached in view of the given model of cross-cultural communication presented above, as well as in view of the general culture-oriented knowledge of the two societies.

\section{Data and discussion}

Table 2 below presents the 20 most distinctive $A D J-V$ pairs in $\mathrm{AE}$ in the construction under investigation. 
ON ELEMENTS OF CULTURALLY INFLUENCED LANGUAGE USE

\begin{tabular}{|l|l|l|c|c|c|c|c|}
\hline Rank & ADJ & V & $\begin{array}{c}\text { Observed } \\
\text { in AE }\end{array}$ & $\begin{array}{c}\text { Observed } \\
\text { in BE }\end{array}$ & $\begin{array}{c}\text { Expected in } \\
\text { AE }\end{array}$ & p-value & $\begin{array}{c}\text { Neg } \\
\text { log10(p) }\end{array}$ \\
\hline 1 & smart & know & 260 & 67 & 165.055 & $1.54 \mathrm{E}-27$ & 26.812 \\
\hline 2 & smart & understand & 78 & 12 & 45.488 & $6.25 \mathrm{E}-13$ & 12.204 \\
\hline 3 & smart & figure & 76 & 16 & 46.494 & $1.86 \mathrm{E}-10$ & 9.731 \\
\hline 4 & smart & realise & 112 & 35 & 74.256 & $2.32 \mathrm{E}-10$ & 9.634 \\
\hline 5 & smart & be & 54 & 7 & 30.834 & $4.77 \mathrm{E}-10$ & 9.321 \\
\hline 6 & healthy & play & 36 & 1 & 18.706 & $5.86 \mathrm{E}-10$ & 9.232 \\
\hline 7 & smart & make & 46 & 5 & 25.781 & $2.51 \mathrm{E}-09$ & 8.6 \\
\hline 8 & smart & do & 53 & 8 & 30.834 & $3.27 \mathrm{E}-09$ & 8.485 \\
\hline 9 & smart & get & 64 & 17 & 40.934 & $1.57 \mathrm{E}-07$ & 6.805 \\
\hline 10 & stupid & vote & 36 & 4 & 20.221 & $1.95 \mathrm{E}-07$ & 6.71 \\
\hline 11 & responsible & own & 23 & 1 & 12.133 & $3.05 \mathrm{E}-06$ & 5.516 \\
\hline 12 & dumb & believe & 36 & 7 & 21.736 & $9.32 \mathrm{E}-06$ & 5.031 \\
\hline 13 & brave & share & 29 & 4 & 16.682 & 0.0000113 & 4.949 \\
\hline 14 & smart & recognize & 31 & 5 & 18.198 & 0.0000133 & 4.875 \\
\hline 15 & dumb & vote & 17 & 0 & 8.595 & 0.0000155 & 4.811 \\
\hline 16 & crazy & think & 40 & 11 & 25.777 & 0.0000593 & 4.227 \\
\hline 17 & important & get & 15 & 0 & 7.583 & 0.0000617 & 4.21 \\
\hline 18 & stupid & believe & 82 & 39 & 61.116 & 0.000165 & 3.782 \\
\hline 19 & old & vote & 70 & 33 & 52.032 & 0.000493 & 3.308 \\
\hline 20 & smart & vote & 15 & 1 & 8.089 & 0.000524 & 3.281 \\
\hline
\end{tabular}

Table 2. Top most distinctive ADJ-V pairs in AE in the ADJ enough to $V$ construction

As can be seen, the data confirm the hypotheses given above that the $A D J-V$ pairs in which the $A D J$ element denotes lack of good judgement or intelligence (stupid, $d u m b, c r a z y)$ and presence of good judgement (smart), are statistically significant for AE. For example, the adjective smart occurs in the most distinctive pair smart - know, as in: Why should he have done that? Are you not smart enough to know better?. As the table above shows, this pair has been observed 260 times in the given construction in AE, whereas it was expected to occur approximately 165 times (in view of the data from $\mathrm{BE}$ ), which according to the outlined statistical procedure produces the $p$-value of 1.54E-27 (i.e. a number well below the usual border $p$-value of 0.05 for statistical significance), which means that the given two lexemes are indeed statistically strongly co-attracted to one another in the given construction in AE. Similarly, the adjective 
stupid and the verb vote (at rank 10 in the given table), as in But if anyone is stupid enough to vote GOP in the election, then I have no hope for America, occurs 36 times in the $\mathrm{AE}$ section of the GloWbE, whereas it was expected to occur approximately 20 times, which also produces a statistically significant p-value of $1.95 \mathrm{E}-07$. Along the same lines, the adjective dumb in the dumb - vote pair at rank 15 in the table above (That's because we have other people in the middle class who are dumb enough to vote against their own interests and support Republicans who will not be happy until the entire tax burden is shifted away from corporations and the wealthy and onto the middle class) occurs 17 times in the AE section of the GloWbE, whereas it was expected to occur approximately 8 to 9 times, which also produces a statistically significant $p$-value of 0.0000155 . Such data may indeed confirm the above view of the dominant U.S. communication style as informal, open, direct, blunt and tending towards the exaggerated.

Some other observations that can be made here (in keeping with the corpusdriven, rather than corpus-based approach, as in the previous case) are as follows. Firstly, one of the most distinctive ADJ-V pairs in the given construction in AE is responsible - own. A closer additional inspection of such examples in the GloWbE revealed that all such examples are used in the context of guns and other firearms, and usually with negation (You have proven beyond a doubt that you are not responsible enough to own a firearm, I don't think you are responsible enough to own a firearm). Secondly, there is a pair with the adjective brave (and the verb share), as in this example: Thank you so much for demystifying, clarifying and being brave enough to share your experience. These and similar examples from the table above may be a reflection of some of the preoccupations and values of the American public, especially in view of the fact they we do not encounter them among the top co-attracted ADJ-V collexemes in BE.

The data above are also important in the following sense. Namely, the ADJ-V pair such as smart-vote (Look at politics: McCain? Obama? Bush? Romney? Really? People aren't smart enough to vote for an honest politician with a 30-year record of absolute integrity and a stunning record of being right about future events) is one of the top twenty statistically most significant ones in AE even though it occurs only 15 times in the AE section of the GloWbE. This testifies to the value of the presented statistical approach (as the statistical prominence of such data might be overlooked if we were to rely only on descriptive statistics, i.e. on raw frequency counts of the occurrence of such pairs in AE). It also provides further credence to the typical U.S. communication style outlined above (the adjective smart, either inside the scope of negation, as it is the case in the example above and in many other examples, or outside of it, as we well see, does not occur in any of the most distinctive ADJ-V pairs in BE). 
ON ELEMENTS OF CULTURALLY INFLUENCED LANGUAGE USE

Table 3 below presents top most repelled ADJ-V pairs in BE in the given construction.

\begin{tabular}{|l|l|l|c|c|c|c|c|}
\hline Rank & ADJ & $\mathbf{V}$ & $\begin{array}{c}\text { Observed } \\
\text { in BE }\end{array}$ & $\begin{array}{c}\text { Observed } \\
\text { in AE }\end{array}$ & $\begin{array}{c}\text { Expected } \\
\text { in BE }\end{array}$ & p-value & $\begin{array}{c}\text { Neg } \\
\text { log10(p) }\end{array}$ \\
\hline $\mathbf{1}$ & smart & know & 67 & 260 & 160.677 & $6.3 \mathrm{E}-27$ & -26.2 \\
\hline $\mathbf{2}$ & smart & understand & 12 & 78 & 44.416 & $6.85 \mathrm{E}-13$ & -12.165 \\
\hline $\mathbf{3}$ & smart & realise & 35 & 112 & 72.487 & $2.54 \mathrm{E}-10$ & -9.596 \\
\hline $\mathbf{4}$ & smart & figure & 16 & 76 & 45.405 & $3.29 \mathrm{E}-10$ & -9.482 \\
\hline $\mathbf{5}$ & smart & be & 7 & 54 & 30.121 & $4.94 \mathrm{E}-10$ & -9.307 \\
\hline $\mathbf{6}$ & healthy & play & 1 & 36 & 18.278 & $5.92 \mathrm{E}-10$ & -9.227 \\
\hline $\mathbf{7}$ & smart & make & 5 & 46 & 25.188 & $2.57 \mathrm{E}-09$ & -8.59 \\
\hline $\mathbf{8}$ & smart & do & 8 & 53 & 30.122 & $3.37 \mathrm{E}-09$ & -8.472 \\
\hline $\mathbf{9}$ & smart & get & 17 & 64 & 39.988 & $1.64 \mathrm{E}-07$ & -6.785 \\
\hline $\mathbf{1 0}$ & stupid & vote & 4 & 36 & 19.76 & $1.97 \mathrm{E}-07$ & -6.706 \\
\hline $\mathbf{1 1}$ & responsible & own & 1 & 23 & 11.86 & 0.00000306 & -5.515 \\
\hline $\mathbf{1 2}$ & dumb & believe & 7 & 36 & 21.242 & 0.00000941 & -5.027 \\
\hline $\mathbf{1 3}$ & brave & share & 4 & 29 & 16.305 & 0.0000113 & -4.946 \\
\hline $\mathbf{1 4}$ & smart & recognise & 5 & 31 & 17.786 & 0.0000134 & -4.873 \\
\hline $\mathbf{1 5}$ & dumb & vote & 0 & 17 & 8.402 & 0.0000155 & -4.81 \\
\hline $\mathbf{1 6}$ & crazy & think & 11 & 40 & 25.192 & 0.0000599 & -4.222 \\
\hline $\mathbf{1 7}$ & important & get & 0 & 15 & 7.414 & 0.0000617 & -4.21 \\
\hline $\mathbf{1 8}$ & stupid & believe & 39 & 82 & 59.709 & 0.000168 & -3.775 \\
\hline $\mathbf{1 9}$ & old & vote & 33 & 70 & 50.841 & 0.000495 & -3.306 \\
\hline $\mathbf{2 0}$ & smart & vote & 1 & 15 & 7.908 & 0.000524 & -3.281 \\
\hline
\end{tabular}

Table 3. Top most repelled ADJ-V pairs in BE in the ADJ enough to $V$ construction

As can be seen, the ADJ-V pairs that are most strongly co-attracted in AE are at the same time quite similar to those that are most strongly repelled ones in BE. In other words, while ADJ-V pairs in which the ADJ element is an adjective such as dumb, stupid or smart are indeed possible in BE - they do actually occur in it as the table above shows, they are statistically not probable enough. This is quite in keeping with the dominant communication style in the UK as outlined above. Namely, for a culture that is typically characterised by low key, modest, retrained and tenacious communication, in which, when people criticise, disagree or even praise, they do it 
obliquely (using understatement and coded speech), it is indeed not to be expected that others would be openly designated as smart, stupid, dumb, crazy (and the like) enough to do something. This can be taken as yet another confirmation of the hypothesis outlined above.

The Tables 4 and 5 below present the most strongly repelled ADJ-V pairs in AE and the most strongly co-attracted ones in BE.

\begin{tabular}{|c|l|l|c|c|c|c|c|}
\hline Rank & ADJ & $\mathbf{V}$ & $\begin{array}{c}\text { Observed } \\
\text { in AE }\end{array}$ & $\begin{array}{c}\text { Observed } \\
\text { in BE }\end{array}$ & $\begin{array}{c}\text { Expected } \\
\text { in AE }\end{array}$ & p-value & $\begin{array}{c}\text { Neg } \\
\text { log10(p) }\end{array}$ \\
\hline $\mathbf{1}$ & good & play & 43 & 148 & 96.222 & $2.92 \mathrm{E}-15$ & -14.535 \\
\hline $\mathbf{2}$ & lucky & be & 159 & 314 & 237.345 & $3.37 \mathrm{E}-13$ & -12.472 \\
\hline $\mathbf{3}$ & lucky & see & 50 & 129 & 90.217 & $1.14 \mathrm{E}-09$ & -8.944 \\
\hline $\mathbf{4}$ & lucky & go & 16 & 68 & 42.398 & $4.07 \mathrm{E}-09$ & -8.391 \\
\hline $\mathbf{5}$ & fit & play & 1 & 26 & 13.642 & 0.000000169 & -6.773 \\
\hline $\mathbf{6}$ & lucky & visit & 5 & 35 & 20.206 & 0.000000627 & -6.203 \\
\hline $\mathbf{7}$ & lucky & play & 7 & 39 & 23.234 & 0.000000865 & -6.063 \\
\hline $\mathbf{8}$ & lucky & own & 3 & 29 & 16.167 & 0.00000113 & -5.948 \\
\hline $\mathbf{9}$ & lucky & get & 169 & 267 & 219.024 & 0.00000137 & -5.863 \\
\hline $\mathbf{1 0}$ & strong & cope & 2 & 25 & 13.642 & 0.00000247 & -5.608 \\
\hline $\mathbf{1 1}$ & lucky & have & 358 & 492 & 424.718 & 0.0000039 & -5.409 \\
\hline $\mathbf{1 2}$ & good & win & 62 & 123 & 93.255 & 0.00000408 & -5.389 \\
\hline $\mathbf{1 3}$ & lucky & witness & 3 & 25 & 14.147 & 0.0000127 & -4.896 \\
\hline $\mathbf{1 4}$ & big & cope & 0 & 15 & 7.581 & 0.0000259 & -4.587 \\
\hline $\mathbf{1 5}$ & good & stay & 3 & 23 & 13.137 & 0.0000419 & -4.378 \\
\hline $\mathbf{1 6}$ & good & say & 6 & 29 & 17.683 & 0.0000598 & -4.223 \\
\hline $\mathbf{1 7}$ & good & challenge & 6 & 29 & 17.683 & 0.0000598 & -4.223 \\
\hline $\mathbf{1 8}$ & good & compete & 11 & 38 & 24.75 & 0.0000786 & -4.105 \\
\hline $\mathbf{1 9}$ & brave & take & 16 & 46 & 31.311 & 0.000103 & -3.986 \\
\hline $\mathbf{2 0}$ & strong & mark & 0 & 13 & 6.57 & 0.000106 & -3.976 \\
\hline
\end{tabular}

Table 4. Top most repelled ADJ-V pairs in $\mathrm{AE}$ in the ADJ enough to $V$ construction 
ON ELEMENTS OF CULTURALLY INFLUENCED LANGUAGE USE

\begin{tabular}{|l|l|l|l|l|l|l|l|}
\hline Rank & ADJ & $\mathbf{V}$ & $\begin{array}{c}\text { Observed } \\
\text { in BE }\end{array}$ & $\begin{array}{c}\text { Observed } \\
\text { in AE }\end{array}$ & $\begin{array}{c}\text { Expected } \\
\text { in BE }\end{array}$ & p-value & $\begin{array}{c}\text { Neg } \\
\text { log10(p) }\end{array}$ \\
\hline $\mathbf{1}$ & good & play & 148 & 43 & 94.339 & $1.64 \mathrm{E}-15$ & 14.784 \\
\hline $\mathbf{2}$ & lucky & be & 314 & 159 & 232.978 & $5.55 \mathrm{E}-14$ & 13.256 \\
\hline $\mathbf{3}$ & lucky & see & 129 & 50 & 88.398 & $7.28 \mathrm{E}-10$ & 9.138 \\
\hline $\mathbf{4}$ & lucky & go & 68 & 16 & 41.516 & $3.99 \mathrm{E}-09$ & 8.399 \\
\hline $\mathbf{5}$ & fit & play & 26 & 1 & 13.349 & $1.66 \mathrm{E}-07$ & 6.779 \\
\hline $\mathbf{6}$ & lucky & have & 492 & 358 & 416.689 & $1.88 \mathrm{E}-07$ & 6.726 \\
\hline $\mathbf{7}$ & lucky & get & 267 & 169 & 214.702 & $4.93 \mathrm{E}-07$ & 6.307 \\
\hline $\mathbf{8}$ & lucky & visit & 35 & 5 & 19.775 & $6.17 \mathrm{E}-07$ & 6.21 \\
\hline $\mathbf{9}$ & lucky & play & 39 & 7 & 22.74 & $8.5 \mathrm{E}-07$ & 6.07 \\
\hline $\mathbf{1 0}$ & lucky & own & 29 & 3 & 15.821 & $1.11 \mathrm{E}-06$ & 5.955 \\
\hline $\mathbf{1 1}$ & strong & cope & 25 & 2 & 13.349 & $2.44 \mathrm{E}-06$ & 5.613 \\
\hline $\mathbf{1 2}$ & good & win & 123 & 62 & 91.334 & $2.87 \mathrm{E}-06$ & 5.541 \\
\hline $\mathbf{1 3}$ & lucky & witness & 25 & 3 & 13.843 & $1.26 \mathrm{E}-05$ & 4.9 \\
\hline $\mathbf{1 4}$ & big & cope & 15 & 0 & 7.417 & $2.57 \mathrm{E}-05$ & 4.59 \\
\hline $\mathbf{1 5}$ & good & stay & 23 & 3 & 12.854 & $4.15 \mathrm{E}-05$ & 4.382 \\
\hline $\mathbf{1 6}$ & good & challenge & 29 & 6 & 17.303 & $5.92 \mathrm{E}-05$ & 4.228 \\
\hline $\mathbf{1 7}$ & good & say & 29 & 6 & 17.303 & $5.92 \mathrm{E}-05$ & 4.228 \\
\hline $\mathbf{1 8}$ & good & compete & 38 & 11 & 24.221 & $7.78 \mathrm{E}-05$ & 4.109 \\
\hline $\mathbf{1 9}$ & brave & take & 46 & 16 & 30.643 & 0.000102 & 3.99 \\
\hline $\mathbf{2 0}$ & lucky & secure & 13 & 0 & 6.428 & 0.000105 & 3.977 \\
\hline
\end{tabular}

Table 5. Top most attracted ADJ-V pairs in BE in the ADJ enough to $V$ construction

As can be seen, the data in the given tables are once again almost like mirror images - the ADJ-V pairs that are most strongly repelled in AE are at the same time most strongly co-attracted ones in BE.

While the results in Tables 2 and 3 were expected in view of the hypothesis presented above, the actual results in Tables 4 and 5 were not. As can be seen, the Tables 4 and 5 are dominated by the pairs in which the ADJ element is either lucky (lucky-be, lucky-see, etc.) or good (good-play, good-win, etc.). Here we will try to provide a possible explanation for this primarily on the basis of general culture-oriented knowledge, stressing thereby that such an explanation only represents a (hopefully) informed opinion, and that the given results deserve further investigation into why they should be as they are (this confirms the fact that running statistical tests may in and of itself be a rather simple task and that a much more complex task is to try and interpret thus obtained results). 
The pairs with the adjective lucky, as in And if ever I'm lucky enough to own another Porsche, I'll consider customizing it, Not every black woman will be lucky enough to have that random chance to get famous and wealthy), are strongly repelled ones in AE. A possible reason for this may be rooted in the U.S. cultural history, namely the Protestant ethic of perseverance, industry, hard work, diligence and personal accountability rather than luck and chance. It is also an established fact that casino-style gambling (as something where luck plays a prominent role) has to this day remained legal state-wide only in Nevada and Louisiana, and that the spin of the roulette wheel is generally looked down on in the USA. So, this might be the reason why pairs such as lucky-own, lucky-have (as in the above examples), as well as the other pairs listed in Table 4 above with the same adjective, while indeed possible, are also not probable enough in AE. On the other hand, the high distinctiveness of such pairs in BE may be a result of both their high statistical improbability in AE, as well as some other factors that require further investigation.

Similarly, the pairs with the adjective good (good-play, good-win, etc.), as in That guy had a really weird career... good enough to play 71 games at age 19, but only 5 games after that, Their performance would have been good enough to win just about any regular season game, that also dominate both tables, are strongly repelled in $\mathrm{AE}$ and strongly co-attracted in BE. A part of the possible explanation for this may be that adjectives whose meaning does not involve great psychological investment (cf. good vs smart / dumb / stupid) indeed tend to be preferred in BE rather than AE.

\section{Conclusions}

The paper has hopefully shown that the combination of reliance on massive corpora (here the GloWbE corpus) approached by a statistical method (here the distinctive collexeme analysis as a type of collostructional analysis theoretically rooted in usage-based construction grammar), the results of which are interpreted qualitatively (here by reliance on the models of cross-cultural communication) can indeed produce some meaningful results pertaining to language-culture interrelation. While thus obtained results require further investigation, the given approach seems to generally be a worthwhile research path to take in the area.

\section{References}

Bergen, B. and K. Binsted (2004). The cognitive linguistics of scalar humor. In: M. Achard and S. Kemmer (eds.), Language, Culture and Mind, Stanford, CA: CSLI. 79-91. 
Davies, M. (2018). Using Large Online Corpora to Examine Lexical, Semantic, and Cultural Variation in Different Dialects and Time Periods. In: E. Friginal (ed.), Corpus-Based Sociolinguistics, London: Routledge, 19-82.

Elsness, J. (2013). Gender, culture and language: Evidence from language corpora about the development of cultural differences between English-speaking countries. In: G. Andersen and K. Bech (eds.), English Corpus Linguistics: Variation in Time, Space and Genre - Selected Papers from ICAME 32, Amsterdam: Rodopi, $113-137$.

Fina M. E. (2011). What A TripAdvisor Corpus Can Tell Us About Culture. Cultus: The Journal of Intercultural Mediation and Communication, 4, 59-80.

Fortuin, E. (2013). The construction of excess and sufficiency from a crosslinguistic perspective. Linguistic Typology, 17, 31-88.

Fortuin, E. (2014). Deconstructing a verbal illusion: The 'no X is too Y to Z' construction and the rhetoric of negation. Cognitive Linguistics, 25(2), 242-292.

Friginal, E. (ed.). (2018). Studies in Corpus-Based Sociolinguistics. New York and London: Routledge.

Gilquin, G. (2006). The verb slot in causative constructions. Finding the best fit. Constructions 1(3), 1-46.

Goldberg, A. E. (1995). Constructions: A Construction Grammar Approach to Argument Structure. Chicago: University of Chicago Press.

Gries, S. T. (2012). Frequencies, probabilities, association measures in usage-/ exemplar-based linguistics: Some necessary clarifications. Studies in Language, $36(3), 477-510$.

Gries, S. T. (2013). Data in Construction Grammar. In: T. Hoffman and G. Trousdale (eds.), The Oxford Handbook of Construction Grammar, Oxford: OUP, 93-108.

Gries, S. T. (2014). Coll. analysis. A script for R to compute perform collostructional analyses (Version 3.5) [Computer software]. $<\mathrm{http}: / / w w w . l i n g u i s t i c s . u c s b . e d u /$ faculty/stgries/teaching/groningen/>.

Gries, S. T. (2015). More (old and new) misunderstandings of collostructional analysis: on Schmid and Küchenhoff (2013). Cognitive Linguistics, 26(3), 505-536.

Gries, S. T. and A.Stefanowitsch (2004a). Covarying collexemes in the into-causative. In M. Achard and S. Kemmer (Eds.), Language, Culture and Mind. Stanford, CA: CSLI, 225-236.

Gries, S. T. and A. Stefanowitsch (2004b). Extending collostructional analysis: A corpus-based perspective on 'alternations'. International Journal of Corpus Linguistics, 9(1), 97-129.

Gries, S. T., B. Hampe, and D. Schönefeld (2005). Converging evidence: bringing together experimental and corpus data on the association of verbs and constructions. Cognitive Linguistics, 16(4), 635-76. 
Hilpert, M. (2014a). Collostructional analysis: Measuring associations between constructions and lexical elements. In: D. Glynn and J. A. Robinson (eds.), Corpus Methods for Semantics: Quantitative studies in polysemy and synonymy, Amsterdam and Philadelphia: John Benjamins, 391-404.

Hilpert, M. (2014b). Corpus-based Approaches to Constructional Change. In: T. Hoffman and G. Trousdale (eds.), The Oxford Handbook of Construction Grammar. New York: OUP, 457-475.

Hoffman, T. and G. Trousdale (eds.). (2013). The Oxford Handbook of Construction Grammar. New York and Oxford: Oxford University Press.

Ivorra Pérez, F. M. (2014). Cultural values and digital discourse: An intercultural communication approach to the transactional discourse of Spanish and US sales websites. Journal of Intercultural Communication, 36, 50-76.

Jensen, K. E. (2015). Adjectives and usage-patterns in the [X enough to VERB]construction. Paper presented at The $13^{\text {th }}$ International Cognitive Linguistics Conference, Newcastle upon Tyne, United Kingdom. (12 December 2018) $<$ https://www.forskningsdatabasen.dk/en/catalog/2398085492>.

Jensen, K. E. (2017). Corpora and Cultural Cognition: How Corpus-linguistic Methodology Can Contribute to cultural Linguistics. In: F. Sharifian (ed.), Advances in Cultural Linguistics, Singapore: Springer, 477-505.

Johnson, M. (1987). The Body in the Mind: The Bodily Basis of Meaning, Imagination, and Reason. Oxford: University of Chicago Press.

Leech, G. and R. Fallon (1992). Computer corpora - what do they tell us about culture? ICAME Journal, 16, 29-50.

Lewis, R. D. (2006). When cultures collide: Managing successfully across cultures. $3^{\text {rd }}$ edition. London: Nicholas Brealey.

Lewis, R. D. (2005). Finland, cultural lone wolf. Yarmouth, ME: Intercultural Press.

Ooi, V. B. (2000). Asian or Western realities? Collocations in Singaporean-Malaysian English. In: J. M. Kirk (ed.), Corpora Galore: Analyses and Techniques in Describing English, Amsterdam: Rodopi, 73-89.

Paradis, C. (2000). It's well weird: Degree modifiers of adjectives revisited: The nineties. In: J. M. Kirk (ed.), Corpora Galore: Analyses and Techniques in Describing English, Amsterdam: Rodopi, 147-160.

Pavlović, V. (2019). Massive corpora and models of cross-cultural communication styles in Cognitive Linguistics: The case of the N1 V (for) N2 to-infinitive construction in English. Review of Cognitive Linguistics (Special issue: Corpus Approaches to Language, Thought and Communication), 17(1), 29-52.

Piller, I. (2007). Linguistics and intercultural communication. Language and Linguistic Compass, 1(3), 208-226. 
Prykarpatska, I. (2008). Why are you late? Cross-cultural pragmatic study of complaints in American English and Ukrainian. Revista Alicantina de Estudios Ingleses, 21, $87-102$.

Sharifian, F. (ed.). (2017a). Advances in Cultural Linguistics. Singapore: Springer.

Sharifian F. (2017b). Cultural Linguistics. Cultural Conceptualizations and Language. Amsterdam and Philadelphia: John Benjamins.

Stefanowitsch, A. (2013). Collostructional Analysis. In: T. Hoffman and G. Trousdale (eds.), The Oxford Handbook of Construction Grammar, Oxford: OUP, 290306.

Stefanowitsch, A. and S. T. Gries. (2003). Collostructions: Investigating the interaction between words and constructions. International Journal of Corpus Linguistics, 8(2), 209-243.

Stefanowitsch, A., and S. T. Gries (2005). Covarying collexemes. Corpus Linguistics and Linguistic Theory, 1(1), 1-43.

Stefanowitsch, A., and S. T. Gries (2008). Channel and constructional meaning: A collostructional case study. In: G. Kristiansen and R. Dirven (eds.), Cognitive sociolinguistics, Berlin and New York: Mouton de Gruyter, 129-152.

Tognini-Bonelli, E. (2001). Corpus Linguistics at Work. Amsterdam: John Benjamins.

Wulff, S., A. Stefanowitsch, and S. T.Gries (2007). Brutal Brits and persuasive Americans: Variety-specific meaning construction in the into-causative. In: G. Radden et al. (eds.), Aspects of meaning construction in lexicon and grammar, Amsterdam and Philadelphia: John Benjamins, 265-281. 